\title{
Geografía histórica y tiempo geográfico, concepto y superación de dicotomías
}

\section{Historical geography and geographical time, concept and overcoming of dichotomies}

\author{
Everaldo Batista da Costa' (1) y Vinicius Sodré Maluly² (1)
}

\begin{abstract}
RESUMEN
Las dicotomías relativas al espacio / tiempo, sociedad / naturaleza y espacio / sociedad aún componen un complejo desafío metodológico en Geografía. Simultáneamente, la geografía histórica es una subárea capaz de leer y producir una representación dialéctica del espacio, por medio del discurso, cartografía e imágenes. Así, este artículo tiene por objeto proponer el concepto tiempo geográfico, constituyente epistémico y ente analítico de problemáticas espaciales transescalares y transtemporales, operadas por la cartografía histórica. Metodológicamente están correlacionadas: i) la geografía histórica y las representaciones escalares del espacio; (ii) la representación cartográfica como posibilidad de superación de la dicotomía espacio / tiempo y; (iii) una praxis cartográfica del tiempo geográfico, en favor de las dialécticas sociedad $\leftrightarrow$ naturaleza y espacio $\leftrightarrow$ sociedad, fundamentada en un caso de estudio del Brasil colonial del siglo XVIII.
\end{abstract}

Palabras clave: geografía histórica, tiempo geográfico, dialéctica espacio-tiempo, cartografia histórica, Brasil colonial.

\begin{abstract}
The space-related dichotomies of time/space, society/nature and space/society are still a complex methodological challenge for Geography. Simultaneously, Historical Geography is a sub-area capable of reading and producing a dialectic representation of space, by discourse, cartography and images. Thus, this article proposes the concept of geographical time, epistemic component and analytic entity of trans-scalar and trans-temporal spatial issues, operated by historical cartography. Methodologically, it correlates: i) Historical Geography and the scalar representations of space; (ii) cartographical representation as means of overcoming the time/space dichotomy; and (iii) a cartographical praxis of geographical time, in support of society $\leftrightarrow$ nature and space $\leftrightarrow$ society dialectics, substantiated in the eighteenth century Colonial Brazil.
\end{abstract}

Keywords: Historical Geography, geographical time, time-space dialectics, historical cartography, colonial Brazil.

Instituto de Ciencias Humanas, Departamento de Geografía, Universidad de Brasilia, UnB, Brasil, DF. Correo electrónico: everaldocosta@unb.br École des Hautes Études en Sciences Sociales (EHESS, Paris). Correo electrónico: vmaluly@gmail.com 
Es un desafío metodológico de la Geografía (campo del saber dedicado al espacio geográfico) la superación -epistémica y de praxis- de las dicotomías espacio/tiempo, sociedad/naturaleza y espacio/sociedad. Dentro de las diferentes ramificaciones del temario geográfico -la urbana, agraria, política, económica, etc.-, la geografía histórica trae consigo una paradoja agravada: la seducción histórica que protagoniza el pensamiento temporal y el espacio asumido, equivocadamente, como una etapa de acciones deslindadas por delimitación de períodos; de manera simultánea, esta subárea es capaz de contribuir, efectivamente, con un análisis metódico, conductor de la superación de esas dicotomías.

Este artículo parte de la hipótesis de que, para superar tales dicotomías desde la geografía histórica, el camino metodológico sería poner en primer plano y evidencia de movimiento el objeto geográfico del análisis, mediante la representación escalar periodizada del espacio (por medio de la cartografía, por ejemplo) sin, con todo ello, congelarlo. Según González Leiva y Bernedo Pinto (2013: 180) “la geografía histórica encuentra en la cartografía una muy buena aliada tanto para la interpretación como para la reconstitución del pasado, por el hecho de tratase de una herramienta que brinda múltiples posibilidades para representar y comunicar un fenómeno que ha tenido lugar en la superficie terrestre". Veremos que el movimiento del objeto geográfico está en el debate dialectizante que fomenta la simultaneidad espacio $\leftrightarrow$ tiempo $\leftrightarrow$ naturaleza $\leftrightarrow$ sociedad, através del caso de análisis de la representación cartográfica de la Capitanía de Goiás en el siglo XVIII.

Debe tomarse en cuenta que muchos análisis potenciales pierden oportunidades epistémicas y metódicas para i) desmitificar el espacio ajeno del tiempo y de la sociedad, ii) des-protagonizar el tiempo en la historia del espacio y iii) deshacer la ruptura entre la voluntad social productiva y la historia ambiental creadora. El poder de las variables dicotomizantes de espacio / tiempo, sociedad / naturaleza y espacio / sociedad -y la historia influenciada con el peso del tiempo pasado- elude el pensamiento y la praxis geográfica.

En síntesis, este artículo tiene como objetivo presentar y analizar, mediante la cartografía histórica, el concepto de tiempo geográfico ${ }^{3}$; tiempo presente-pasado o el ente continente totalizado y totalizante del espacio. Las representaciones del tiempo geográfico -discurso, cartografía e imágenes- deben ser capaces de dimensionar e impulsar la interescalaridad y la transtemporalidad espacial. Esa postura teórico-metodológica exige una noción sensorial del espacio entrenada, así como una perspicacia dialéctica representacional.

Metodológicamente, el artículo relaciona (i) la geografía histórica y las representaciones escalares del espacio, (ii) la representación cartográfica como posibilidad de superación de la dicotomía espacio / tiempo y (iii) propone una praxis cartográfica del tiempo geográfico, en favor de las dialécticas sociedad $\leftrightarrow$ naturaleza y espacio $\leftrightarrow$ sociedad, situada en el Brasil colonial del siglo XVIII.

\footnotetext{
Nuestra definición de tiempo geográfico no es la misma que la utilizada por Fernand Braudel en sus conocidos estudios sobre el Mediterráneo. Según Braudel (2017 [1949]), el tiempo geográfico es "una historia casi inmóvil" de las relaciones entre la humanidad y la naturaleza. Una historia "casi fuera del tiempo", que "corre lentamente". Ese tiempo geográfico es el fundamento de la primera parte de El Mediterráneo, titulado "La parte del medio". La segunda y tercera partes son estructuradas en concepciones de tiempos históricos y sociales. Así, a pesar de Braudel sugiere una "geo-historia" (concepción presente solamente en la primera edición de El Mediterráneo), el autor busca aún una disociación entre lo que sería marcadamente geográfico e histórico. Este artículo fomenta un tiempo geográfico dialéctico que no quiere separar, pero unir, superando dicotomías.
} 


\section{Geografía histórica, representaciones escalares del espacio y tiempo geográfico}

La periodización histórica y la regionalización geográfica (delimitación de conjuntos espaciales de todas las escalas) son recortes de objetos intelectuales indispensables, pues es imposible estudiar todo sobre absolutamente todo (Grataloup, 2015). Sin embargo, cualquier representación escalar periodizada del espacio debe, dialécticamente, sintetizar y totalizar la sociedad en sus conexiones históricas. Encontrar, a través de la categoría espacio, las dimensiones territoriales constitutivas de la sociedad exige abordar el mundo, sus representaciones y contradicciones operadas por sistemas espaciales abiertos, de larga duración y contenido de tiempos desiguales. “Podríamos hablar de un tiempo espacial propio a cada lugar [...]. La presencia simultánea de variables con temporalidades tan diversas resulta en que la combinación característica de cada lugar es única" (Santos, 1978: 257-258).

En ese sentido, para solucionar las dicotomías espacio / tiempo, sociedad / naturaleza y espacio / sociedad (que conjunta y operativamente conforman la categoría espacio geográfico), ${ }^{4}$ el camino metodológico, desde la geografía histórica, será involucrar, imprescindible y simultáneamente: i) la subjetividad de la historia del territorio; ii) la objetividad de la representación del dato o del fenómeno en tanto acontecimiento transtemporal y transescalar, así como iii) la concreticidad del objeto situado y en situación espacial duradera 5 .

Las manifestaciones violentas de la naturaleza (una erupción volcánica o un terremoto) no definen la formación ni el carácter de los individuos; sino que es la recíproca determinación del ambiente que genera efectos sobre hechos y acontecimientos históricos (Fochler-Hauke, 1953). La interacción sociedad-naturaleza es una decisión política de grupos humanos localizados, en movimiento y selección espacial; la naturaleza denominada, dominada y socializada, en su origen y travesía, refleja la sociedad en su devenir.

Baker (2005) examina cuatro contribuciones de la geografía histórica a la Geografía: i) la tradición de la localización, que engloba de manera puntual el estudio de las distribuciones geográficas en el espacio así como su difusión en el tiempo; ii) la tradición ambiental, que enmarca los estudios sobre rehabilitación de ambientes pasados o las modificaciones procesales de la naturaleza para el hombre, o bien como historia de la percepción cultural del ambiente; iii) la tradición, producción y significación del paisaje, vinculado a los historiadores, antropólogos, novelistas, poetas, artistas y fotógrafos, y iv) la tradición regional, que cuestiona los conceptos de personalidad geográfica, áreas culturales y de geografía histórica regional, nacional y mundial; tradición en la cual los atlas históricos hacen la síntesis de la historia y de la geografía de los lugares. Baker (2015) reconoce, aún, una geografía histórica aplicada dedicada a la temática patrimonial, cuyo precursor fue Robert Newcomb (1979) con su trabajo Planning the past: historic landscape resources and recreations. Este autor teorizó sobre la utilización y el planeamiento del "pasado visible" de los paisajes históricos como atractivos y de los museos en tanto lugares de "peregrinaciones

\footnotetext{
Como ámbito de lo social -además de la base económica, del orden político y jurídico y de las superestructuras ideológicas- el espacio geográfico no es el mero reflejo del modo de producción actual, sino la memoria de los modos de producción del pasado, detentor del contenido de los demás ámbitos (Santos, 1978; Souza, 2019).

Ver en Costa (2016) la noción de situación espacial duradera.
} 
patrióticas". Una geografía preocupada por la preservación y utilización recreativa del pasado (en esa línea, se presenta en Costa, 2016a, el concepto de paisaje barroco como memoria estética nacional, aplicado a Brasil y América Latina).

Tales contribuciones de la geografía histórica demuestran la diversidad del campo disciplinario, a veces envuelto con la distribución espacial de los fenómenos y su difusión en el tiempo; en ocasiones involucrado en la historia de la apropiación de los ambientes naturales, y en otras preocupado por la producción de los paisajes o con el planeamiento del pasado visible. Por eso, los análisis potenciales pierden oportunidad epistémica y metódica para (i) desmitificar el espacio separado del tiempo y de la sociedad, (ii) des-protagonizar el tiempo en la historia del espacio y (iii) deshacer la ruptura entre la voluntad social productiva y la historia ambiental creadora. La historia emerge como potencial variable dicotomizante, pues la importancia del tiempo confunde el pensar y la praxis geográfica. ${ }^{6} \mathrm{H}$. Capel percibe diferentes velocidades entre los cambios de la sociedad y los cambios del espacio; asimismo, reconoce la simultaneidad pasado-presente para la geografía histórica.

“El pasado es un extraño país, y es siempre una reconstrucción, porque ya no está [...]. Pero el cambio de la sociedad y del espacio tiene ritmos diferentes en sus elementos constitutivos, y algunos pueden transformarse más deprisa que otros. Hay formas del pasado que permanecen todavía hoy, en un presente en el que se han modificado otros muchos elementos, tanto materiales como inmateriales. Por ello, el pasado puede estar presente en el espacio de una u otra forma; deja, en efecto, restos diversos, y a través de ellos persiste, y nos obliga a dialogar con él, a tomar actitudes respecto al mismo; ellos nos interesan porque ayudan a entender las raíces del presente" (Capel, 2009: 5, las cursivas son nuestras).

Muchas investigaciones, por desconocimiento, negligencia o -es preferible pensar que- por didáctica y filiación metodológica se refuerzan esas dicotomías, a veces queriendo negarlas. El hecho es que las "investigaciones de geografía histórica pueden ser de interés para examinar con argumentos históricos un problema actual de gran trascendencia", o también "la geografía histórica puede ser útil para organizar el presente y construir el futuro", pues, "la mirada al pasado permite reflexionar sobre avances y retrocesos en el curso de la historia", cuando "el mundo actual actúa con olvido de esas lecciones del pasado, como si aceptáramos que el progreso será constante e indefinido y que no habrá retrocesos, especialmente en los países desarrollados" (Capel, 2006: 2-7).

En síntesis, la importancia teórica, metodológica y de praxis de la geografía histórica puede estar en la proposición de un tiempo geográfico -distinto del tiempo histórico puntual en la circunscripción y en la petrificación de los hechos y fenómenos-; es decir, centrada en el espacio↔tiempo $\leftrightarrow$ sociedad, no perdido o congelado en el pasado, sino comprendido en su devenir totalizador, en una palabra: representado. El tiempo geográfico es el tiempo presente-pasado o el ente continente totalizador del espacio. Las representaciones del tiempo geográfico -a través del discurso, la cartografía y las imágenes- deben ser capaces de dimensionar e impulsar la interescalaridad y la transtemporalidad espacial. Como se ha mencionado, tal postura conceptual y

\footnotetext{
El protagonismo del tiempo en el espacio también puede tener efectos sustanciales sobre el imaginario de un lugar, considerando el "atraso" o el "avance" espacial según una perspectiva moderna de "tiempo". A ese respecto, ver Agnew (1996).
} 
metodológica exige a su vez una noción sensorial aguda del espacio y una perspicacia dialéctica representacional?.

Tiempo geográfico no es sinónimo de espacio geográfico, sino un componente de su contenido, favorece la interpretación genética de la simbiosis sociedad $\leftrightarrow$ naturaleza y la correspondencia transtemporal y transescalar de espacio $\leftrightarrow$ sociedad. Esa lectura inhibe influencias metodológicas dicotomizantes que se arrastran desde el período clásico de la disciplina hasta los días actuales, como se ve en dos (y en otras) escuelas geográficas de América Latina: México y Brasil.

Los geógrafos mexicanos J. O. Moncada y P. Gómez-Rey resaltan el significado de la producción geográfica académica de su país (siglos XIX y XX) en la identificación de lo que denominaran bienes naturales conformadores del patrimonio geográfico de México. Los autores dejan una importante muestra de análisis del territorio con énfasis en los obstáculos naturales como teatro del devenir social, y reclaman la ausencia de textos sobre la geografía de México que superen la dimensión naturalizante del espacio. ${ }^{8}$ Notables geógrafos brasileños reconocen que "la naturaleza es un plano de fundamento en el repertorio lingüístico de la Geografía" (Moreira, 2012: 23). Esto es, por más que gane fuerza, en el país, la concepción discursiva del espacio como término de unidad de la interacción sociedad $\leftrightarrow$ naturaleza, el hecho es que las cosas siguen divididas: i) muchos de los llamados geógrafos físicos profundizan en los sistemas naturales tanto de la superficie como de las profundidades terrestres y marinas, perdiendo de vista el horizonte de las problemáticas humanas y de la socialización ambiental; ii) los heraldos de la geografía crítica radicalizan la dimensión abstracta del espacio, en un determinismo economicista que impide la vuelta a la apariencia y al tiempo geográfico (de extensión existencial) promotor de la dialéctica espacio $\leftrightarrow$ tiempo, sociedad $\leftrightarrow$ naturaleza y espacio $\leftrightarrow$ sociedad.

Pitte (2005) afirma que esa subárea no es un saber gratuito; debe ser socialmente coherente, erudita y propositiva, pues las ideas nuevas son liberadas a ese precio; si ella no produce, directa o indirectamente, una vida mejor para la humanidad podría desaparecer, así como toda la Geografía. En sus propias palabras: "La geografía histórica o la geografía en general, muchas veces, corre el riesgo de caer en la especulación puramente intelectual" (Pitte, 2005: 201). La geografía histórica puede contribuir, por ejemplo, a que países que no basen su identidad en la cohesión social y cultural -en las Américas y África, en especial- eviten guerras civiles, dictaduras y segregación étnico-espacial. Perspectiva que se aproxima de una geografía histórica aplicada al servicio de la paz; también se puede vincular a usos recreativos y didácticos del pasado.

Así, la geografía histórica aliada con la cartografía gana notoriedad "por la variedad de temas que en ella es dable abordar, en atención a su capacidad de mostrar gráficamente cualquier tipo de fenómeno que pueda ser localizado [...] ya sea éste de naturaleza concreta o abstracta, de

\footnotetext{
En parte, esa propuesta dialoga con Santos (1978), quien entiende el espacio como un sistema de relaciones, en el que el tiempo es tomado como variable concreta; el tiempo empírico, en la dimensión de la extensión y no de la métrica. En este artículo se revisa lo que Santos denomina sucesión de sistemas temporales y de sistemas espaciales como fundamento de la explicación para las situaciones actuales. No tratamos de sucesiones, sino de simultaneidades de sistemas espacio↔temporales aprendidos en la periodización; el hecho o fenómeno registrado es explicado por la simultaneidad de momentos y de las conexiones de las acciones pasadas-presentificadas; la sucesión de tiempos y espacios no se relaciona con la lógica dialéctica.

\& Por ejemplo, Cabrales (2018), Alvarado (2019), Cabrales (2018) Azevedo \& Torres (2020) y García Fernández (2020) superan dicha dimensión en su estudio sobre historia, territorio y memoria en México.
} 
modo dinámico o estático, y en una dimensión cualitativa o cuantitativa" (González Leiva \& Bernedo Pinto, 2013: 180).

Reconocemos a la geografía histórica como subárea contrubuyente a indagaciones epistémicas y de problemáticas factuales del espacio transtemporal y transescalar. Esa perspectiva exige lectura y producción representacional dialéctica del espacio a través del discurso, la cartografía y las imágenes, incorporando el tiempo geográfico y la simultaneidad de sistemas conformadores del pasado-presentificado, a fin de superar las clásicas dicotomías de las que se ha venido hablando: espacio / tiempo, sociedad / naturaleza y espacio / sociedad.

\section{Representación cartográfica en geografía histórica: superación de la dicotomía espacio / tiempo}

Definido el tiempo geográfico y la cuestión de las dicotomías conceptuales, expondremos un análisis que busca superar dichas oposiciones, además de una geografía histórica reflexivo-estratégica con las necesidades humanas situadas. Clark (1952) defiende que esa subárea presenta herencias de la Geografía, para la comprensión del mundo contemporáneo, por medio del estudio del pasado y de la cualificación del futuro. Si el debate sobre la funcionalidad de la Historia remite al supuesto auxilio del pensamiento sobre el futuro, es posible concordar que el tiempo geográfico vuelve sustancial el análisis del pasado, del presente y del futuro. ${ }^{9}$ La pretendida simbiosis espacio↔tiempo integra dos fundamentos de la vida (la situación y la duración) y puede fomentar investigaciones totalizadoras. Como se dijo antes, un camino didáctico para esa superación está en la consideración de la interescalaridad y de la transtemporalidad espacial, dentro de la que se encuentran las cartografías históricas.

La cartografía es una técnica milenaria de representación del espacio y se asocia con la Geografía desde el siglo XVI (Bord, 1997), con atribuciones altamente estratégicas en contextos políticos, militares y religiosos (Moncada, 2018; Costa \& Moncada, 2021). A partir del siglo XIX, ocurre el entrecruzamiento de la estadística y las técnicas cartográficas (Palsky, 1996; González Leiva, 2007); lo que favorecerá la producción de los mapas temáticos y su amplia difusión en los siglos XX y XXI, como beneficio de la revolución digital. El desafío asumido es el de superar la dicotomía espacio / tiempo -por medio de la cartografía histórica-, sin promover distinciones drásticas entre las diferentes formas de acceso y de producción de los mapas; el parámetro es una concepción crítica de cartografía histórica. En nuestro caso de análisis, una perspectiva crítica sobre la producción de mapas en el Brasil colonial y también sobre las posibilidades cartográficas actuales. Sin embargo, el mapa en sí no es la única alternativa a la superación de las dicotomías geográficas, dada la materialidad inherente a la cosa; los mapas deben contribuir con el "método de espacialización del pensamiento" (Lois, 2015: 3). La cartografía histórica resulta de la represen-

Santos (1996: 31) afirma, en alerta con respecto a los riesgos aportados por el anacronismo, que la geografía histórica no puede simplemente hacer recolecciones de "instantes disparatados y distantes de la misma flecha del tiempo", sino encontrar maneras fidedignas de "volver a trazar el pasado" 
tación de una consciencia datada del espacio y los objetos deben ser cartografiados a través de la consciencia del tiempo geográfico.

¿Cualquier representación espacial producida en el pasado es objeto de la cartografía histórica? ¿Las que hoy se producen no lo serían? Estas cuestiones tienen un carácter preliminar y apuntan hacia otras indagaciones relativas a la superación de la dicotomía espacio / tiempo desde la geografía histórica.

Consideremos cualquier representación cartográfica elaborada en el pasado como cartografía antigua; no es necesario diferenciar lo que sería histórico o no, admitiendo que, si el mapa fue elaborado en periodos distantes del presente será nombrado mapa antiguo, lo que no excluye su carácter "histórico". Las representaciones producidas en el pasado tienen un "presente" y un "pasado" como referencias simultáneas. Un cartógrafo en su trabajo de campo, haciendo notas de lo que ve, mediciones del terreno y abusando de las evidencias territoriales previamente cartografiadas, debe tener la habilidad de construir un producto sintético desde la área y no sólo eso, puesto que se ha anclado en un espacio↔tiempo que recolecta hechos y fenómenos transescalares y transtemporales. Son incorporados en esa labor la precisión requerida de los saberes matemáticos y el ideal de verdad, reflejado en los saberes artísticos (Verdier, 2016; Moreno Jeria, 2018). Eso le otorga al mapa un carácter cuádruple situacional entremezclando el localizar con el representar, el trasntemporalizar y el interescalarizar. Así, el mapa antiguo resulta de prácticas y estructuras espacio-temporales, de las que sobresale el paisaje como primer contacto del cartógrafo con el territorio (lo que es visto) y la racionalidad estratégica de la representación (lo que es imaginado y proyectado). Crespo Sanz y Fernández Wyttenbach (2011) ofrecen una lectura similar con relación a los mapas antiguos y a los mapas historicos, añadiendo la característica "obsoleta" de la cartografía antigua. Según los autores, "se puede calificar como cartografia antigua la que se conserva desde tiempos pasados y se ha quedado obsoleta en algún sentido, mientras que la cartografia histórica sería la relativa a la historia, o la que representa aspectos historicos" (Crespo Sanz \& Fernández Wyttenbach, 2011: 414).

La cartografía histórica, por tanto, no es solamente lo que hace referencia a una cartografía antigua. Esto es, que mapas contemporáneos, a pesar de no ser antiguos, pueden ser considerados históricos cuando fueron elaborados en correspondencia a fenómenos y hechos espaciales pasados; aunque sean producidos con técnicas actuales. De manera que las visualizaciones cartográficas son formas válidas y sustanciales de lenguaje y de análisis espaciales, además de históricas (Barleta \& Gil, 2015), independientemente de la época en que fueron producidas. La Figura $\mathrm{N}^{\circ} 1$ permite visualizar, más claramente, lo que se puede entender por una cartografía histórica contemporánea. 
Figura $\mathrm{N}^{0} 1$.

Mapa de las rutas fluviales y terrestres del "extremo oeste"

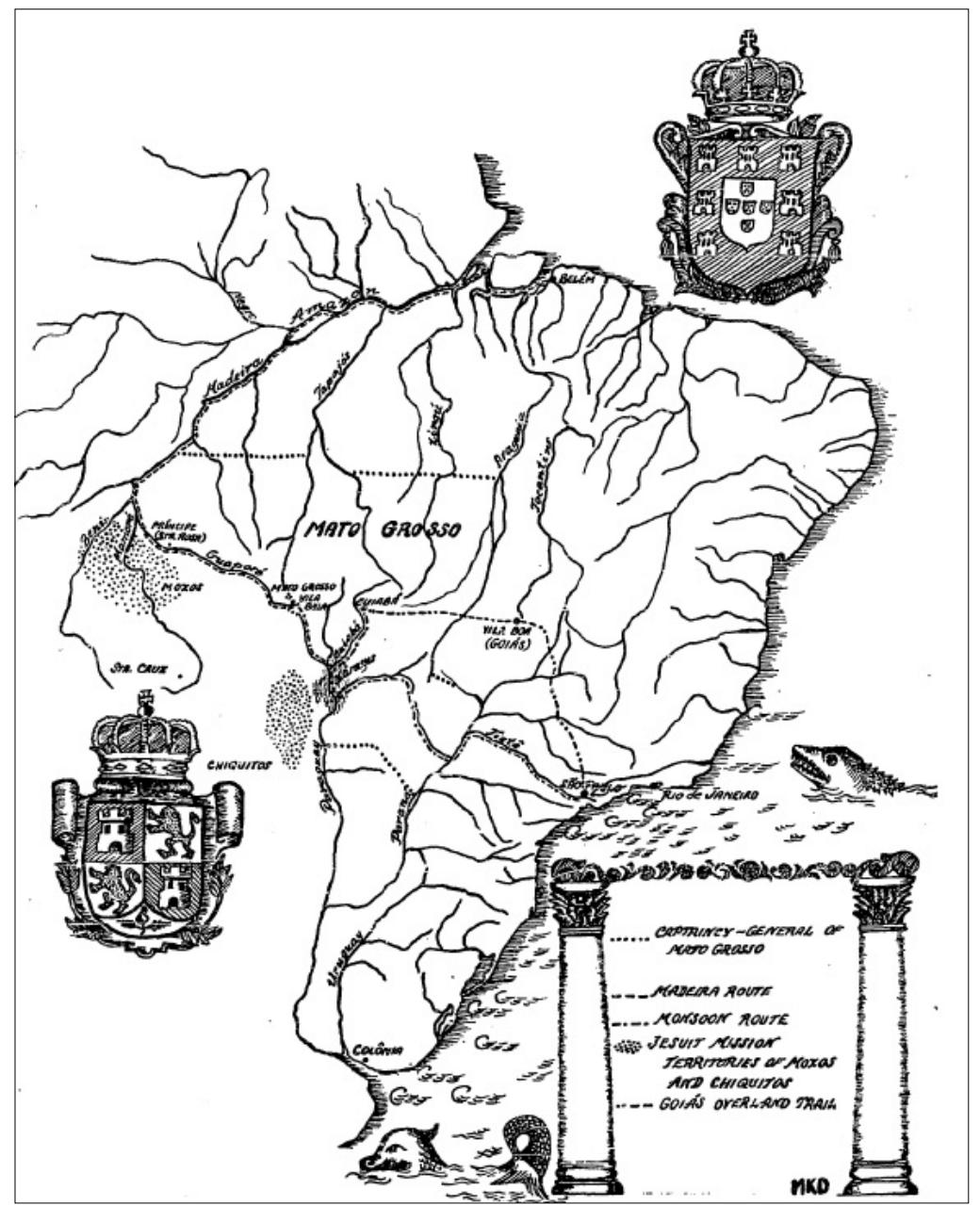

Fuente: Davidson, (1970: xi)

El mapa elaborado por David Davidson, en la década de 1970, traduce algunas inquietudes de su doctorado y contempla, espacialmente, la distribución de algunos caminos y rutas comerciales que conectaban parte del territorio colonial brasileño con la Capitanía de Mato Grosso, en el "extremo oeste". El mapa fue elaborado hace cerca de medio siglo, desde una vasta serie documental, con datos de la formación paulatina de los caminos, los cuales buscaban superar (i) la naturaleza inhóspita en muchos puntos, (ii) las relaciones de convivencia entre indígenas y españoles en los trayectos, (iii) además de las barreras político-administrativas impuestas por la Corona Portuguesa en lo que concernía a la apertura de nuevos caminos; en especial de los caminos reales. ${ }^{10}$ Davidson elabora una cartografía histórica transtemporal y transescalar al localizar

\footnotetext{
Charles Boxer (1962), en The golden age of Brazil, 1695-1750, argumenta que, después del fervor inicial producido por los descubrimientos auríferos de las regiones mineras, la Corona Portuguesa tuvo que establecer un control sobre la extracción y la circulación de los recursos a lo largo de la creciente red de caminos que se expandia al interior de la colonia. Ejemplos de eso fueron los dos bandos expedidos en 1701 de los cuales, el primero se proponía cerrar la ruta del río São Francisco que llevaba a la Capitanía de Bahía, y el segundo tornaba obligatoria la portación de pasaportes asignados por gobernadores para entrar y salir de las minas.
} 
y negar la concepción de periferia que se atribuía a su área de estudio, superando la dicotomía entre tal área y el centro-sur evocado por el discurso nacional, así como estimular construcciones interpretativas al territorio colonial del oeste.

El objeto histórico (afecto al tiempo geográfico que, nuevamente, no se traduce en espacio geográfico, sino que efectivamente lo constituye) se concreta por la interpretación cartográfica de la historia del territorio. La instrumentalización de la operación geográfica no se conduce sólo mediante la lectura del mapa antiguo (importante en las investigaciones geohistóricas), sino también por la construcción de la cartografía histórica. Para Morrissey (2014: 283), “al formularnos la imagen de un espacio específico, de un tiempo del pasado, representaciones contemporáneas -escritas o visuales- proveen lentes clave a través de las cuales podemos ver". Es un punto de inflexión del tiempo geográfico con hechos o fenómenos representados (consciencia formulada y modeladora de la transescalaridad $\leftrightarrow$ transtemporalidad simultánea) que la superación de la dicotomía espacio / tiempo (reforzada por la separación institucional de la Geografía y de la Historia) parece concretar.

No se puede perder de vista la importancia imaginativa y política de los mapas antiguos. Parte de esa cartografía (siglos XVI y XVII, en el caso de Brasil) fue producida a partir de una "geografía fantástica" que "impulsaba la revelación de los sertones"11, desde los inicios de la colonización portuguesa. Mitos de la flora y fauna salvaje habitaban la mente de los cartógrafos, los cuales incluían en sus producciones monstruos marinos y terrestres que caracterizaban un territorio desconocido. No obstante, con el gradual conocimiento y uso del territorio, la "geografía fantástica" es sustituida por la "geografía realista"12, visible en las producciones cartográficas del siglo XVIII. Fonseca (2011) confirma la disminución de la perspectiva mitológica en la cartografía colonial. Durante doscientos años de colonización portuguesa, las leyendas cartográficas comenzaron a desaparecer de los mapas, dando lugar a una cada vez más "rigurosa" y "objetiva" producción. Nuevamente, la creatividad artística y la racionalidad matemática se interponen, fundamentalmente, en la interpretación de la cartografía. El uso político de esas visualizaciones es emblemático en términos de la historia del territorio. Y, Conforme a Moraes (2009: 64),

[...] los territorios coloniales son ámbitos espaciales de pretensión de soberanía interpuestos entre las metrópolis europeas, áreas formalmente delimitadas de supuesta jurisdicción de una autoridad metropolitana, de fronteras vagas o hipotéticas (más establecidas en los mapas que en el terreno). Las regiones cartográficas que acompañan los tratados europeos de repartición de las colonias bien expresan lo afirmado. También en su imprecisión, los límites pactados sirven de referencias geopolíticas prácticas. La gran producción de cartografía lusitana sobre Brasil demuestra la importancia de ese instrumento en la diplomacia de la definición de las fronteras interamericanas.

El mapa antiguo inserta una representación espacial política. Debe ser reconocido el carácter oficial instituido en el tratamiento de esas fuentes, por las preocupaciones relativas a conexiones y a las duraciones estratégicas del ideal de economía espacial colonial. Mucho de lo que se repre-

Moraes (2009: 89) clasifica sertão como una ideología geográfica atribuida a determinadas partes del territorio "según la mentalidad reinante y los intereses vigentes", con "valores culturales [...] negativos, los cuales introducen objetivos prácticos de ocupación o reocupación de los espacios enfocados".

2 Sobre esa geografía, ver Straforini (2007). 
sentaba cartográficamente no reflejaba la realidad necesariamente vivida. Por ejemplo, territorios en disputa por dos Coronas podían ser colocados de uno u otro lado de la frontera, dependiendo de dónde provenía el financiamiento cartográfico. Mapas producidos con el sello de intereses de la Corona divergían, notoriamente, de mapas elaborados a partir de necesidades episcopales ${ }^{13}$.

En ese punto, el espacio↔tiempo gana simbiosis. Dando una interpretación simbólica, política $y$, en diferentes grados, creativa de la cartografía; esto es, los mapas transmutan de una conversión estética fría de la realidad espacial a una simbolización del tiempo geográfico específico de aquella realidad. Un topónimo o el límite de una frontera deben ser asumidos por la cartografía histórica como el poder y el control duradero del territorio, elementos balizadores del devenir geográfico y social.

Si un mapa de época colonial (con "geografías fantásticas" seductoras del imaginario colonizador) proporciona una visión del territorio en constitución, en el contexto político y social de la estrategia del reino (sin olvidar al sujeto cartógrafo), ¿cómo podría contribuir la cartografía histórica contemporánea a la superación de las dicotomías geográficas, más allá del espacio / tiempo?

\section{Praxis cartográfica del tiempo geográfico: dialécticas sociedad $\leftrightarrow$ naturaleza y espacio $\leftrightarrow$ sociedad en los setecientos de la Colonia brasileña}

La producción cartográfica es inherente a la Geografía por representar, esencialmente, el territorio en escalas. Así, elaborar un mapa es, antes de todo, retratar aspectos específicos de determinado territorio, de los procesos geográficos y del poder. Como es referido por Gomes (2018: 132), las "imágenes participan directamente en la construcción del pensamiento geográfico". Sin embargo, las relaciones dicotómicas sociedad / naturaleza y espacio / sociedad han suscitado disonancias en las investigaciones y en la política, por retratar comprensiones polémicas en las producciones intelectuales y prácticas de la Geografía, además de autorizar violencias gubernamentales en los usos del territorio. Según Sauer (1996 [1925]), el desafío disciplinario sería: dar sentido totalizante a aquello que se percibe en el paisaje. Lo anterior está en la coexistencia y la interacción de los objetos y de las acciones que surgen de la aptitud geográfica en atribuir significado a los hechos y fenómenos espaciales y no al separarlos o congelarlos. La interacción sociedad $\leftrightarrow$ naturaleza y la comprensión espacio $\leftrightarrow$ sociedad puede ser expresadas por la cartografía histórica, pero no es la única forma. El tiempo geográfico es el catalizador primero y último de la realidad espacial, de lo visible y lo invisible relativos a la sensibilidad geográfica; es contributivo a la unidad de ese conocimiento, pues vuelve dialéctico el propio espacio.

\footnotetext{
Butlin (1993) refuerza el carácter esencial que las producciones geográficas históricas tuvieron, durante el siglo XIX para teorías y emprendimientos coloniales. Cuestiones relativas a actuaciones metropolitanas o nacionales eran construidas a partir de nociones geohistóricas y cartográficas, en todo el mundo. Chile es un ejemplo. En el siglo XIX, se realizaron levantamientos cartográficos del territorio nacional, debido al proyecto político nacido junto con la independencia, asegurando el futuro de la nueva entidad soberana (González Leiva, 2007; Sagredo Baeza, 2018)
} 
Tratar las dicotomías del pensamiento disciplinario desde la cartografía histórica significa valorar el corazón del "raciocinio geográfico". Gomes (2018) plantea que la "imaginación geográfica" ocurre visualmente y no solamente por medio de la cartografía, sino que se sirve de cualquier forma de expresión de los "sistemas de informaciones geográficas", hasta en la misma evocación imaginativa del texto. En la década de 1920, Carl Sauer afirmaba que la expresión más precisa del conocimiento geográfico se encontraba en el mapa, un símbolo inmemorial. En la misma década, Camille Vallaux (1927) afirma que la "observación visual" es el procedimiento esencial común a la Geografía y a otras ciencias naturales, pero que la "observación refractada", por medio de la cartografía resulta natural y particular de la ciencia geográfica. En 1952, A. Clark decía que un geógrafo-historiador desentrenado o desinteresado por la geografía física y cartografía era una anomalía. La cartografía histórica debe estar vinculada al conocimiento geográfico, localizando y situando el objeto histórico en el ininterrumpido movimiento pasado↔presente.

Las consideraciones desarrolladas sobre la cartografía histórica antigua se suman a las posibilidades de comprensión de la historia del territorio por una cartografía histórica contemporánea. Eso fundamentará la discusión sobre una praxis cartográfica del tiempo geográfico en el Brasil Colonial, para dar respuesta a las cuestiones levantadas. La cartografía histórica contemporánea puede contribuir en la aproximación de la concreción del objeto inmerso en transescalaridades y transtemporalidades, con las cuales el tiempo geográfico totaliza los fenómenos y hechos espaciales. El mapa pasa a expresar el soporte intelectual de procesos y de fenómenos recolectados y evidenciados en esa praxis cartográfica.

La Figura $\mathrm{N}^{\circ} 2$, de inicio del siglo XIX, resulta de la historia territorial de los siglos XVI, XVII y $X \mathrm{XIII}$, interpretada en los siglos XX y XXI. Hubo un momento en el que la administración de la Capitanía de Mato Grosso produjo una gran cantidad de mapas, definiendo sus fronteras con el oeste o las colonias españolas (Araújo, 2015). En virtud de los límites de tratados globales, ${ }^{14}$ la cartografía es utilizada en el ejercicio de composición administrativa y territorial del "extremo oeste" brasileño. El mapa simboliza un esfuerzo pasado de representación detallada del territorio, para asegurar los límites entre las Coronas portuguesa y española. Es posible especular sobre la estructura necesaria para viabilizar ese proyecto cartográfico de proporciones continentales, dado el grado de detalles perceptibles también en pequeñas escalas. Para Araújo (2015), la elaboración de esa cartografía tenía por esencia un esfuerzo totalizante de la América portuguesa, puesta la función limítrofe del gran territorio. En tanto una cartografía alternativa podía ser producida en el intento de definir las fronteras internas de la colonia portuguesa, las preocupaciones mato-grossenses tenían una escala más amplia, enfocadas en el contacto con los territorios españoles de frontera.

Tratado de Madrid (1750) y Tratado de San Ildefonso (1777), principalmente. Con respecto a la definición de los tratados políticos y sus impactos tanto en las esferas políticas europeas cuanto en las esferas locales de vida, ver Herzog (2015). 
Figura $\mathrm{N}^{\circ} 2$

"Carta geográfica de la Capitanía de Mato Grosso"

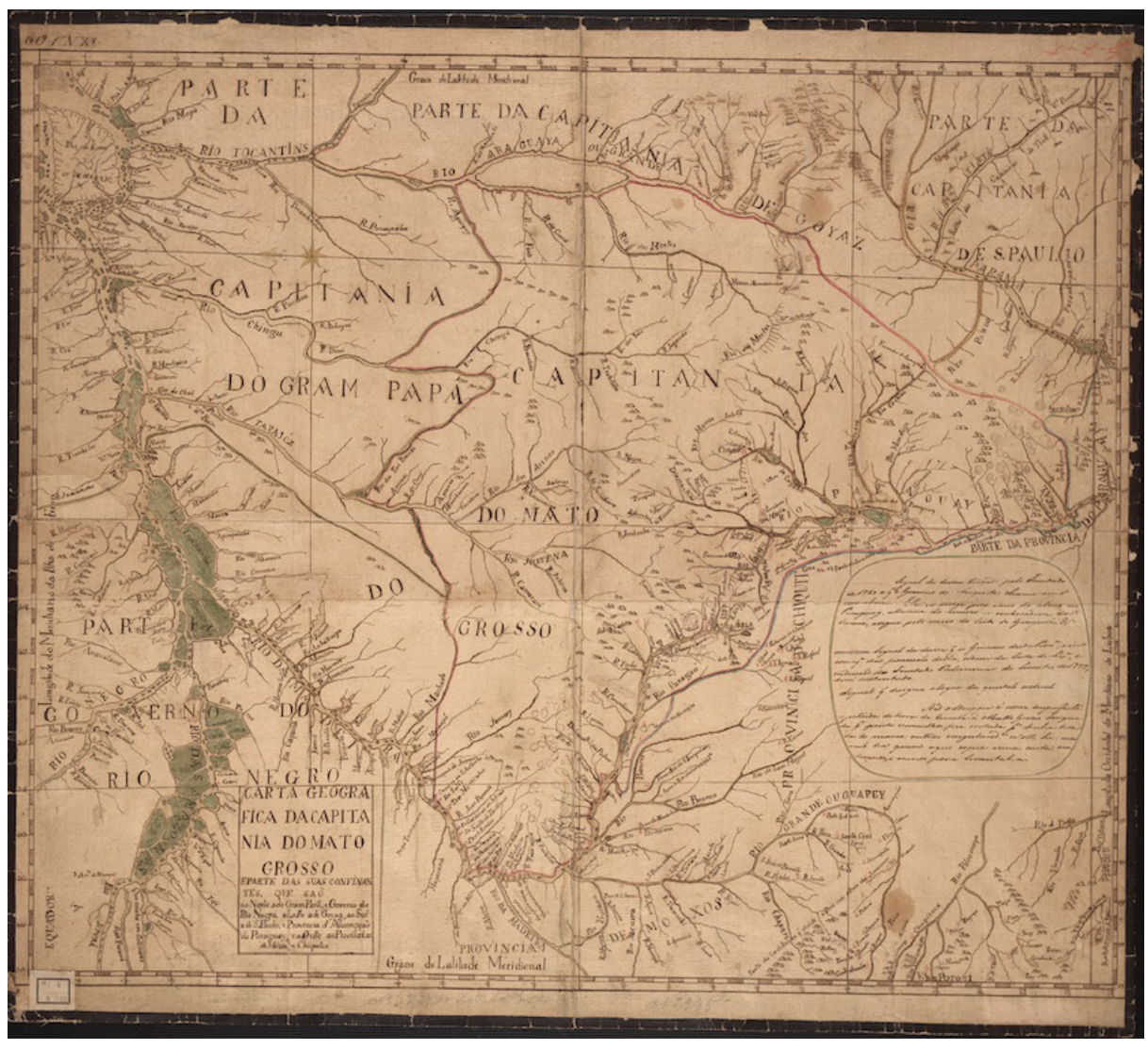

Fuente: Archivo de la Biblioteca Nacional (Brasil), [s.a.], 1800.

Esas consideraciones revelan facetas político-administrativas de la cartografía histórica antigua, con enlace de intenciones y de proyectos territoriales retratados. Para Holanda (2014: 105) "lo más importante era la posesión segura de una extensa área que escapara de la demarcación de Tordesillas y, a partir de esa área, de los límites que ganaba en detrimento del castellano". Entendimientos posteriores al respecto de la presencia portuguesa al oeste, conformando el territorio colonial, pasan por considerable reinterpretación histórico-geográfica.

La atención portuguesa estaba en los límites oeste del territorio; otras capitanías (Figura $\mathrm{N}^{\circ} 3$ ) no eran objeto de cartografía detallada. Un ejemplo significativo es el de la Capitanía de Goiás, la cual tuvo una producción de mapas importantes hasta la primera mitad del siglo XVIII, correspondiente a su intensidad de la minería. El desarrollo minero portugués en Brasil fue acompañado de una cartografía peculiar. Una serie de mapas trata de los núcleos urbanos y caminos surgidos a partir de la actividad. Sin embargo, determinadas zonas de esa capitanía no fueron representadas cartográficamente, denotando lo que Vasconcelos (1999) define por hiato temporal. ${ }^{15}$ Para

15 Por el contenido de este artículo, cabría hablar de hiato espacial, en nombre de la integralidad geográfica del espacio $\leftrightarrow$ tiempo. 
ciertos territorios y épocas, hay un esfuerzo cartográfico notable, para otros, la estructura no fue representada, lo que no implica la ausencia de hechos y fenómenos históricos. En ese caso, ¿la dicotomización espacio / sociedad sería justificada por la ausencia documental? ¿Tal ausencia sería una razón para separar la lectura de esos territorios del tiempo geográfico? Lo grave está en el hecho de que la sociedad no representada se torna una abstracción mediante el poder. Por el carácter dispendioso de las expediciones cartográficas, los mapas retrataban el territorio al gusto del financiador. Cuando el oro asume una importancia secundaria, por la disminución del papel definitorio de las fronteras del oeste, a finales del siglo XVIII, la cartografía histórica antigua comienza a perder fuerza.

Figura $\mathrm{N}^{\circ} 3$

"Brazil"

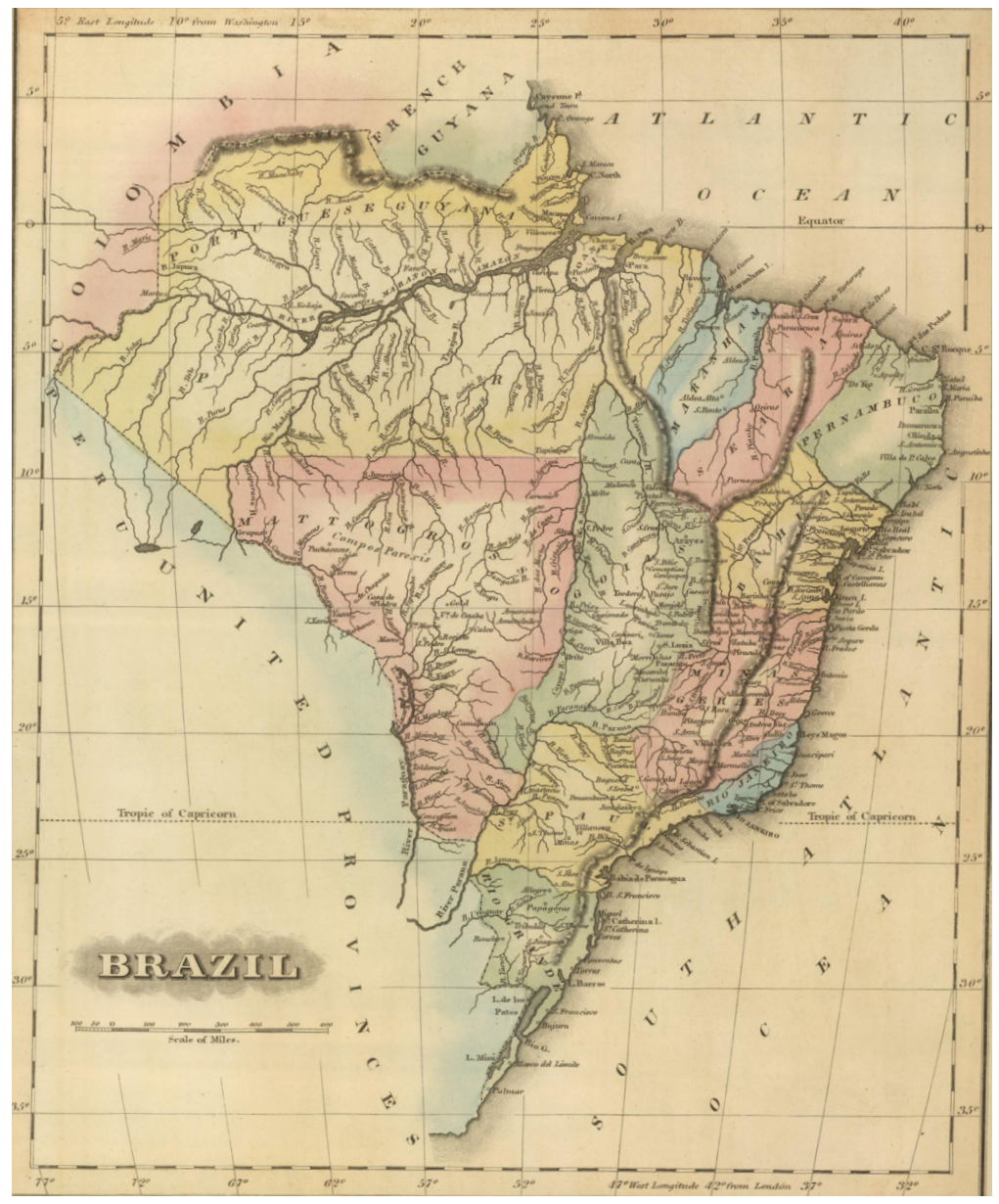

Fuente: David Rumsey Map Collection, 1817.

Consecuentemente, las pesquisas geográficas e históricas acompañan la mayor o la menor disponibilidad de imágenes del territorio, pues el acceso a fuentes direcciona el estudio y la aprensión concreta del objeto. Al asociar la producción cartográfica con la investigación a ella referente, se identifica la gran cantidad de trabajos que se reflejan sobre las zonas de frontera y, en 
el mismo corte temporal, otras partes del territorio no tienen la misma atención de los geógrafos. Éste es el caso de los territorios que estaban proximos a las nuevas fronteras definidas a partir de los tratados globales ya aludidos. Tales hiatos dicotomizantes (temporales espaciales) no son productos únicos de la negligencia epistémica, sino también del sentido atribuido al territorio por el Estado. La geografía histórica puede superar las dicotomías sociedad / naturaleza y espacio / sociedad tomando tales elementos no como complementariedad del espacio palco, sino totalizando, por la cartografía o cualquier otra forma de representación o narrativa del espacio pretérito, el tiempo geográfico, que activa el espacio dialéctico o la dialéctica del espacio.

La Figura N4, elaborada para este trabajo, busca superar esas dicotomías, que no son solamente materiales, sino también como comprensión del territorio colonial. En ese caso, conseguimos retratar los registros y las contagens fiscales ${ }^{16}$ de la Capitanía de Goiás, hasta el año de 1752, información que se encontraba muy dispersa y poco retratada en los mapas antiguos. ${ }^{17}$ Para efecto de la producción de esa cartografía, los hechos fueron recogidos en fuentes escasas $^{18}$, dando continuidad a otras investigaciones sobre el tema, añadiendo estas informaciones a un relieve aproximado. Con base en esa cartografía histórica contemporánea, interpretaciones renovadas sobre la historia del territorio colonial brasileño se hacen posibles, como los flujos de contrabando que eran más frequentes por el lado oriental de la Capitanía. El relieve accidentado (sierras y valles) posibilitaba la movilidad necesaria, por donde la Corona Portuguesa instalaba sus aparatos fiscales. Abreu (1899: 189), en referencia a esa parte de la Capitanía, habla de "angosturas seguramente ya recorridas por indios" por donde habría contacto entre las tierras goianas y baianas. Lo mismo se puede comprender de la instalación de los aparatos fiscales en puntos de encuentro de los caminos más utilizados, para controlar y contabilizar la entrada y salida de productos y personas en la Capitanía. La franja oriental visualizada en la Figura 4 demuenstra la síntesis sociedad $\leftrightarrow$ naturaleza, por el tránsito de personas y gestión de mercancías. Metodológicamente, se pone el objeto geográfico de análisis en primer plano y evidencia de movimiento, a través de la representación tranescalar y periodizada del espacio. La narrativa textual sustenta y complementa el mapa, para alcanzar la dialética espacial desde la noción del tiempo geográfico en tanto fundamento del método.

16 Objetos geográficos instalados en el territorio colonial, durante el periodo de la recaudación de impuestos denominada quinto de oro, con la intención de controlar la entrada y salida de productos y de recursos minerales. Pueden ser comprendidos como casas de cobranza aduanera en el periodo de minería.

17 El periodo abordado se limita al año de 1752, año de la legalización de la ruta Madeira-Mamoré-Guaporé, que ligaba la Capitanía de Mato Grosso al Estado de Grão-Pará, y por ser el año de creación de la casa de fundición del pueblo de São Félix en la Capitanía de Goiás. Para informaciones más profundizadas al respecto, ver Maluly (2017; 2020).

18 Localizadas, principalmente, en el catálogo "Goiás" del Archivo Histórico Ultramarino (Portugal) y también en la bibliografía especializada aquí citada, como Bertran (1996), Rocha Júnior (2012), Salles (1992) y Vieira Júnior (2015). 
Figura $\mathrm{N}^{\circ} 4$

Registros y contagens de la Capitanía de Goyaz hasta el año de 1752

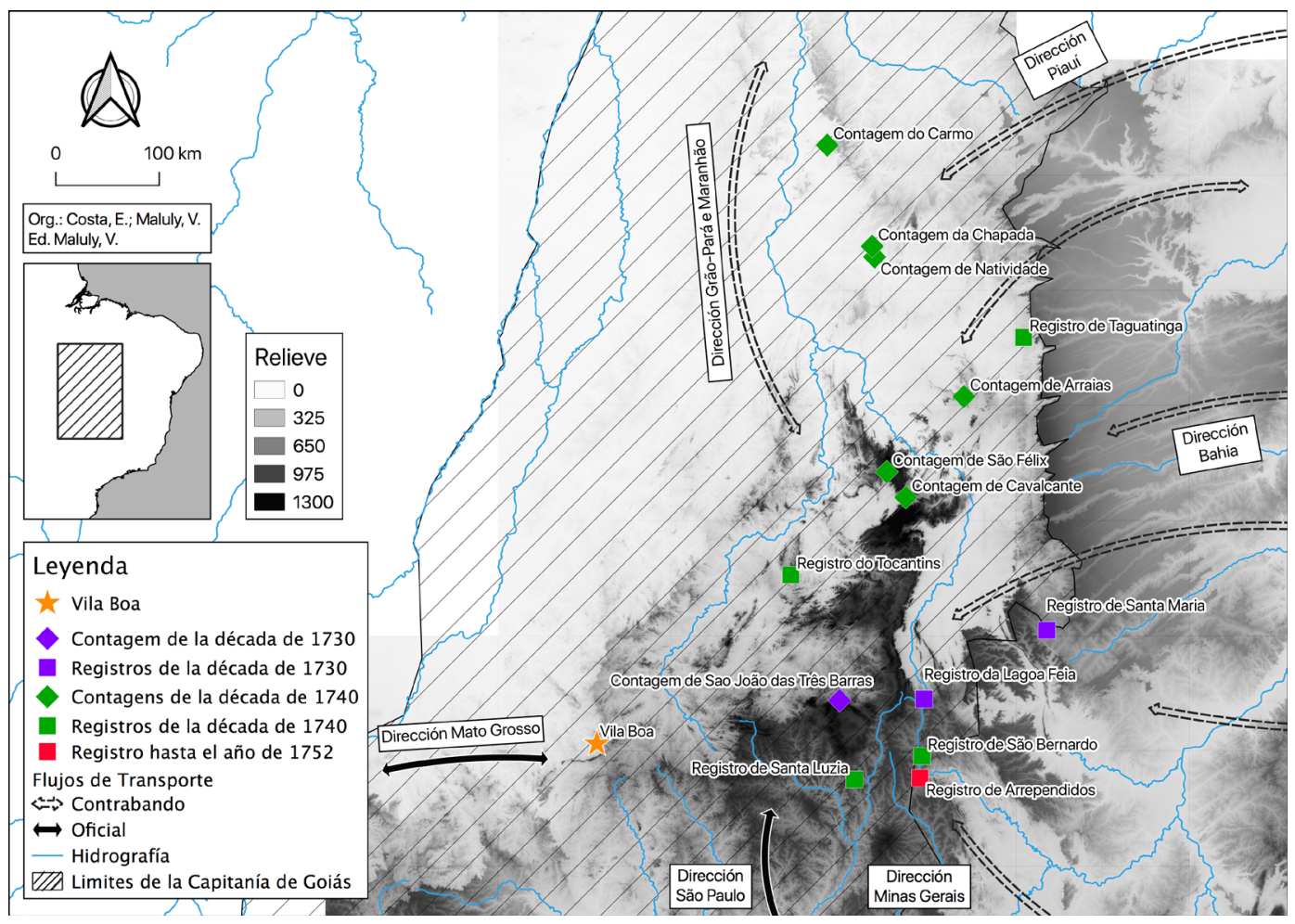

Fuente: Elaboración propia.

Pasamos a actuar, inadvertidamente, en campos no limitados por las dicotomías sociedad / naturaleza y espacio / sociedad. Si, a partir de la segunda mitad del siglo XVIII, hay carencia de representaciones cartográficas sobre la Capitanía de Goiás y una excesiva producción de mapas sobre la Capitanía de Mato Grosso, es posible concebir la espacialización goiana desde otras fuentes, disponiéndolas con el uso de las técnicas de una cartografía histórica contemporánea. De esa manera, no sólo se llenan los "vacíos cartográficos" o los "hiatos temporales", sino que se ofrece un nuevo material de investigación. El caso mencionado de los registros y de las contagens es emblemático; por ser escasos en la cartografía antigua, su localización se hace difícil cuando se consideran apenas tales fuentes. Sin embargo, al elaborar el mapa que representa esos objetos geográficos específicos de la historia colonial brasileña, damos cabida al tiempo geográfico y ofrecemos una nueva posibilidad interpretativa, además de histórica y geográfica, historiográfica. La Figura $\mathrm{N}^{\circ} 5$ proporciona la comprensión radicalmente contraria, pues enfoca un solo momento del movimiento centro-periferia que escinde sociedad / naturaleza y espacio / sociedad. Como se ha dicho anteriormente, la representación escalar periodizada del espacio (discursiva, cartográfica o imagéticamente) debe, dialécticamente, sintetizar y totalizar la sociedad en sus conexiones históricas, siempre que haya fuentes. 


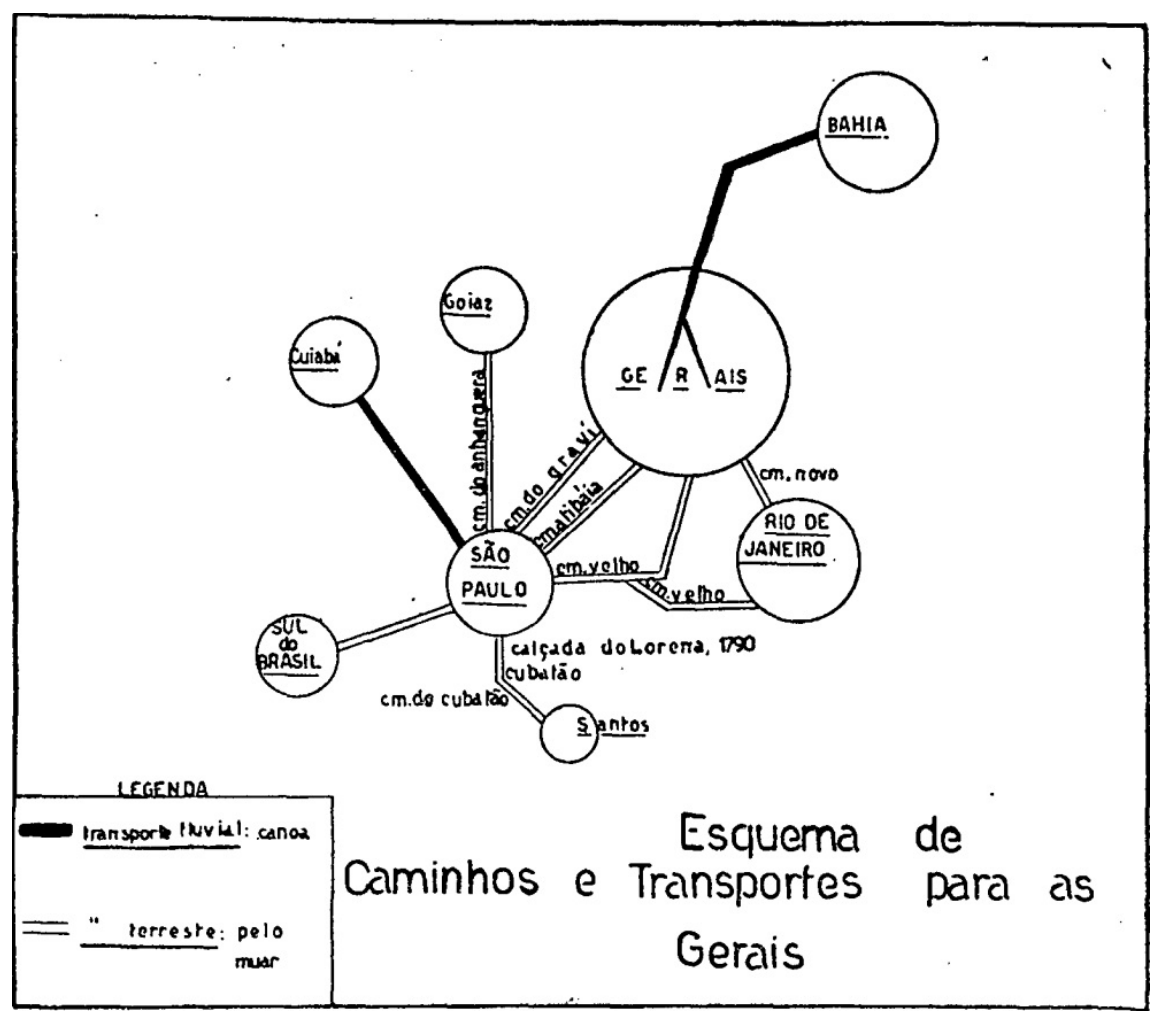

Fuente: Austregésilo (1950: 509)

La Figura $\mathrm{N}^{\circ} 4$ hace percibir que, progresiva y periódicamente, eran instalados registros y contagens en el límite oriental y rumbo al norte de la Capitanía de Goiás, definiendo los territorios actuales de los estados de Tocantins y Goiás; ya la Figura $N^{\circ} 5$ demuestra el espacio congelado. Esos objetos geográficos tenían, esencialmente, la función de controlar la cantidad de productos que entraban y salían de la jurisdicción, considerando el oro extraído, animales y sus derivados ${ }^{19}$. De esa manera, la intención del control portugués, en ese territorio específico, se justificaba por el contacto que la Capitanía de Goiás tenía con otras, como la de Bahía. A su vez, la historiografía que subyace en la producción de la Figura $N^{\circ} 5$, anclada en divisiones que dicotomizan el espacio geográfico, creó posibilidades interpretativas que privilegian el discurso nacional propio del siglo XX, protagonista del centro-sur. De acuerdo con Ingold (2013), no se puede desasociar, enteramente, la dinámica del movimiento de la formación del saber. Sólo cuando captamos el movimiento y el tiempo geográfico a él asociado es que podemos desdoblarlo, tanto en sus significados materiales histórico-geográficos como en sus significantes simbólicos historiográficos. Como ya se dijo, el desafío para aproximarnos al sentido de la

Salles (1992: 159-160) dice que en "su casi totalidad, los registros estaban localizados en las proximidades de la frontera este de Goiás con Minas Gerais, Bahía, Piauí y Maranhão [...]. Se daba preferencia en asentarlos en áreas donde la apertura de huecos favorecía el contrabando". 
totalización social en geografía histórica está en tratar, imprescindible y simultáneamente: i) la subjetividad de la historia del territorio; ii) la objetividad de la representación del hecho o del fenómeno en tanto acontecimiento transtemporal y transescalar y iii) la concreción del objeto situado y en situación espacial duradera.

El contacto entre Mato Grosso, Goiás y Bahía no existe en el mapa de Austregésio que retomando la naturaleza metafórica del mapa $^{20}$ - se apropia del mismo cuadro territorial hasta aquí abordado, pero de manera antagónica. Efectivamente, el espacio / tiempo dicotomizado es visible y discursivamente esquematizado. Ese movimiento dado por la cartografía quiere enseñar una simultaneidad de espacializaciones en una periodización de la historia del territorio a un espacio desprovisto de esa dinámica y apartado de la naturaleza socializada. Esa dicotomía espacio / tiempo / sociedad / naturaleza ocurre a partir de un ideario espacial que no prioriza el tiempo geográfico, sino que se legitima en una proyección del territorio con lectura de las transformaciones por lo alto; o sea, valorizando intencionalidades anacrónicas al recorte del análisis, distorsionando y moldeando el discurso geohistórico (Moraes, 1999).

La Figura $N^{\circ} 6$ presenta las conexiones establecidas por los caminos (oficiales y de contrabando) con los territorios adyacentes, también hasta el año de 1752, en la Capitanía de Goiás. En consonancia con los objetos geográficos puestos en relevancia en la Figura $\mathrm{N}^{\circ} 4$, es notable que la distribución de las vías de comunicación, así como la de los núcleos de poblamiento, durante el auge minero goiano, no mostraba una canalización territorial en dirección a centros de distribución. Al contrario, esos caminos se diseminaban al interior de la Capitanía y también la interconectaban a las Capitanías adyacentes de Mato Grosso, Bahía, Minas Gerais, además de São Paulo, Rio de Janeiro, Piauí y del Estado de Grão-Pará y Maranhão, materializándose los flujos de transporte identificados en la Figura $N^{\circ} 4{ }^{21}$. Así, el caso de estudio goiano, en tanto espina dorsal del sertão colonial en 1700, es emblemático, pues posibilita superar las dicotomías arbitrarias que confunden el pensamiento geográfico. Como ya se ha comentado, los análisis potenciales pierden oportunidad epistémica y metódica para i) desmitificar el espacio separado del tiempo y de la sociedad, ii) desprotagonizar el tiempo en la historia del espacio y iii) deshacer la ruptura entre la voluntad social productiva y la historia ambiental creadora. 
Figura $N^{\circ} 6$

Distribución de los caminos de la Capitanía de Goyaz, con los territorios adyacentes,

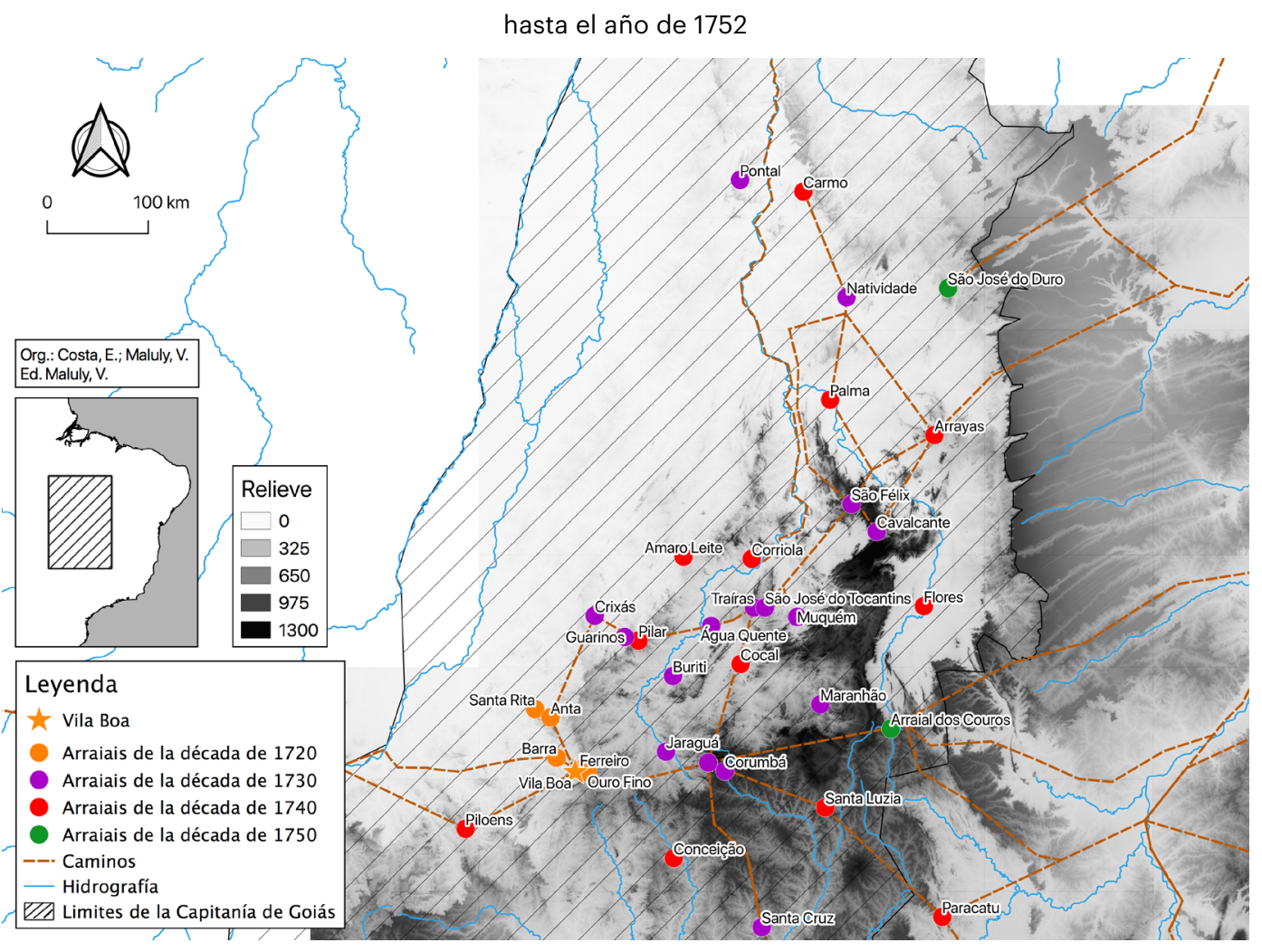

Fuente: Elaboración propia

Como ya se mencionó, la importancia teórica, metodológica y de praxis de la geografía histórica está en el tratamiento de un tiempo geográfico -distinto del tiempo histórico hábil en la circunscripción y en el endurecimiento de los hechos y fenómenos-, inherente al espacio nunca perdido o petrificado en el pasado, pero anclado en su devenir totalizado y totalizador, en una palabra: presentificado. Si el tiempo geográfico es el tiempo presente-pasado o el ente continente totalizado y totalizante del espacio, sus representaciones - por el discurso, la cartografía y a través de las imágenes- deben ser capaces de dimensionar e impulsar la interescalaridad y la transtemporalidad espacial.

Podemos distinguir, en la Figura 6, además de la espacialización ya citada de los arraiais ${ }^{22}$ y de los caminos en la Capitanía de Goiás frente al relieve de la región, el recorte de los núcleos urbanos, periodizados. Esos arraiais de minería tenían una distribución específica para cada época y para cada aspecto del relieve, alterándose conforme pasaban las décadas; el reconocimiento imagético de ese fenómeno es esencial en la construcción de una percepción de la relación con el

El término arraial, a finales del siglo XVII, designaba a viviendas y rozas que los bandeirantes creaban a lo largo de los caminos, para asegurar su sobrevivencia; en el siglo XVIII, cuando el objetivo de las banderas no era más el indígena, sino el oro y diamantes; el término arraial se tornó cada vez más asociado a los poblados de las zonas mineras de la colonia (Fonseca, 2011; Costa, 2011). 
tiempo geográfico. Por esa cartografía histórica contemporánea, espacio-tiempo son dialectizados, en la medida en que se caracterizan, simultáneamente, localización-función-período de este conjunto de objetos geográficos, en movimiento procesal en el contexto de la estructura colonial. Los caminos también siguen esa suerte, pero su periodización es, documentalmente, más desafiante que la de los arraiais, puesto que no podemos ligarlos directamente a la existencia de esos núcleos poblacionales. Ellos efectivamente podrían anteceder la existencia de los arraiais, como también podrían ser reorganizados a partir de la instalación administrativa portuguesa en ese sertão colonial. Holanda (1957) explica la transposición de los conocimientos localizacionales de los indígenas a los bandeirantes que adentraban en el territorio. La clasificación de los caminos ${ }^{23}$ se torna difícil para la investigación geohistórica, debido a las pocas evidencias documentales (como la oficialización de la ruta São Paulo-Goiás, en 1730). Con todo, podemos asociarlos al movimiento transescalar y transtemporal en relación con los arraiais. La totalidad de esos elementos compone nuestra argumentación y lógica territorial aprendida de las fuentes primarias referenciadas.

Buscamos superar un obstáculo que dicotomiza sociedad / naturaleza y espacio / sociedad, puesto que el movimiento representado (consustanciado por los caminos de oro) tenía una dispersión mucho mayor de lo que se reproducía. La conexión forzosa traducida en la Figura $N^{\circ} 5$ -entre una periferia minera y un centro de distribución- refleja menos la realidad espacial de la época, pues excluye numerosos circuitos del territorio. Con un exceso de material sobre el límite al oeste de Brasil (caso de la Figura $N^{\circ} 2$ ), se sabe menos de su movimiento interno, principalmente en términos cartográficos, que conectaba las diversas partes del sertão colonial (como los caminos entre Goiás y Bahía). A partir de la cartografía histórica contemporánea (con organización y uso de las fuentes y datos históricos) es posible construir representaciones del espacio que hacen superar la falta de material para investigación. En ese intento, espacio↔tiempo, espacio↔sociedad y sociedad $\leftrightarrow$ naturaleza constituyen, en resumen, el espacio geográfico a ser entendido en su concreta interescalaridad y transtemporalidad, por la función del tiempo geográfico responsable de ser no sólo visualizado, sino también construido.

\section{Palabras finales}

Las cuestiones de carácter metodológico desarrolladas quieren promover la geografía histórica como subárea de la Geografía capaz de revelar y de superar, distintamente, dicotomías que marcan el pensamiento de esa ciencia. Pensar el espacio revitalizándolo a partir de lo que definimos como tiempo geográfico es asumir la simultaneidad en la espacialización de las escalas y temporalidades. Como postulado, la totalización del espacio es la manera de comprenderlo y también reproducirlo, según los aportes derivados de la investigación geohistórica, presentificándolo socialmente. Desproveer el espacio del movimiento (dicotomizándolo y emancipándolo

\footnotetext{
La definición de camino debe pasar una interpretación. El camino puede ser denotado materialmente (una carretera que se define y se amplía, o puntos de cobranza estratégicamente dispuestos en el territorio), sino también hay un concepto de camino que transciende esa composición física; aquello que es producido a partir del movimiento. La confrontación se da por la cuestión material y denominaciones conceptuales que estructuran un camino en tanto idea. Debemos considerar una reflexión crítica del camino, que es una idea antes que cosa, a pesar de tener en la cosa la totalidad encarnada que reproduce, a su vez, ideas en un movimiento de espacialización. Denominar ya es dar existencia a la cosa. Ver el debate en Andrade (2013; 2021), Andrade \& Andrade (2019), Costa (2011) e Maluly (2017; 2020).
} 
de la naturaleza, de la sociedad y del tiempo), cartográfica y epistemológicamente, es asumir la irresponsabilidad de negar la esencia de la coherencia científica de la Geografía.

En la mitad del siglo pasado, Andrew Clark ya defendía la inseparabilidad entre geografía física y geografía humana. El autor dejó pistas de los campos a recorrer en lo que denominó geografía física histórica. El debate dialectizante de sociedad $\leftrightarrow$ naturaleza de ese geógrafo corrobora con las cuestiones aquí tratadas, tanto en términos del desajuste de las dicotomías, como para nuestra tesis de que el hilo conductor que viabiliza el movimiento dialéctico de las representaciones (cartográficas, discursivas o imagéticas) es el tiempo geográfico, definidor conceptual y material de las transescalaridades y transtemporalidades de los objetos geográficos.

La totalización de los objetos geográficos representados debe reunir, confrontar y significar el espacio, siempre, por medio de la simultaneidad espacio $\leftrightarrow$ tiempo $\leftrightarrow$ naturaleza $\leftrightarrow$ sociedad organizada según la cognición sensorial. Simultaneidad responsable de la interpretación y reconstrucción, por medio de la relación entre la cartografía histórica antigua recuperada y la cartografía histórica contemporánea construida. Problemáticas específicas del mundo colonial, en Brasil o América Latina, pueden ser enfrentadas y recalificadas con ese enfoque metodológico, para pensar el presente nacional dramático y proyectar el futuro.

La historia del territorio se reconstruye a cada descubrimiento técnico y tecnológicos, en correlación con las intencionalidades políticas del periodo.

\section{Referencias}

ABREU, C. Os caminhos antigos e o povoamento do Brasil, En: PAIM, A (ed.). Descobrimento do Brasil e povoamento. Bahia: Centro de documentação do pensamento brasileiro, s.d., 1899, p. 175-260.

AGNEW, J. Time into Space: The Myth of 'Backward' Italy in Modern Europe. Time Society, № 5; 27, p. 27-45, 1996. Disponible en: http://tas.sagepub.com/cgi/content/abstract/5/1/27

ALVARADO, I. Territorio, memoria e imaginario del trabajo: la hacienda y el Ejido Colectivo en Nueva Italia, México. PatryTer, Revista Latinoamericana e Caribenha de Geografía e Humanidades, 2019, Vol. 2, №3, p. 8-25. https://doi.org/10.26512/patryter.v2i3.23063

ANDRADE, A. O outro lado da baía: a gênese de uma rede urbana colonial. Salvador: Edufba, 2013.

ANDRADE, A. Estudos em Geografia Histórica e seu vínculo ao patrimônio-territorial. PatryTer, Revista Latinoamericana e Caribenha de Geografia e Humanidades, 2021, Vol. 4, No 7, p. 63-77. https://doi.org/10.26512/patryter.v4i7.27062

ANDRADE, A., \& ANDRADE, J. Cartografia, dinâmica territorial e patrimônio material: análise a partir do oeste baiano no setecentos. PatryTer, Revista Latinoamericana e Caribenha de Geografía e Humanidades, 2019, Vol. 3, № 2, p. 49-60. https://doi.org/10.26512/patryter.v2i3.19355 
ARAÚJO, R. Os Mapas do Mato Grosso. Terra Brasilis, 2015, No 4, p. 1-13. http://terrabrasilis.revues. org $/ 1230$

AUSTREGÉSILO, M. Estudo sobre alguns tipos de transporte no Brasil Colonial. Revista de História, 1950, Vol. 1, No4, p. 455-516.

AZEVEDO, E., \& TORRES, L. Modos de vida, sostenibilidad y patrimonialización del territorio purépecha, México. PatryTer, Revista Latinoamericana e Caribenha de Geografía e Humanidades, 2020, Vol. 3, No 5, p. 1-13. https://doi.org/10.26512/patryter.v3i5.25783

BAKER, A. Reflexions sur les relations entre l'histoire et la géographie. En: BOULANGER, P.; TROCHET, J. (eds.). Où en est la Géographie Historique? Paris: L'Harmattan, 2005, p. 34-55.

BERTRAN, P. Notícia geral da Capitania de Goiás em 1783. U. Cat. de Goiás, Goiânia, 1996.

BORD, J. Le géographe et la carte. Point de vue et questionnement de la part d'un géographe cartographe. Cybergeo: European Journal of Geography, 1997, № 17, p. 1-28. https://doi.org/10.4000/ cybergeo.6470

BOXER, C. The golden age of Brazil, 1695-1750. California: University of California Press, 1962.

BRAUDEL, F. La Méditerranée et le monde méditerranéen à l'époque de Philippe II. Paris: Armand Colin, 2017.

BUTLIN, R. Historical Geography: Through the Gates of Space and Time. Edward Arnold, Londres, 1993.

CABRALES, L. Paisaje industrial y sus representaciones: La fábrica "La Parisiense" de Guadalajara durante el Porfiriato. PatryTer, Revista Latinoamericana e Caribenha de Geografia e Humanidades, 2018, Vol. 1, No 2, p. 1-28. https://doi.org/10.26512/patryter.v1i2.9355

CAPEL, H. La geografía histórica y la respuesta a los problemas del mundo actual. Scripta Nova. Revista electrónica de geografía y ciencias sociales, 2006, No 218, p. 01-09. http://www.ub.edu/ geocrit/sn/sn-218-96.htm

CAPEL, H. La historia, la ciudad y el futuro. Scripta Nova. Revista electrónica de geografía y ciencias sociales, 2009, № 307, p. 01-34. http://www.ub.edu/geocrit/sn/sn-307.htm

CLARK, A. Historical Geography: Status of Research in American Geography. Division of Geology and Geography National Research Council, Washington D.C.,1952.

COSTA, E. Utopismos patrimoniais pela América Latina: resistências à colonialidade do poder. Actas XIV Colóquio Internacional de Geocrítica, Barcelona, 2016, p. 1-32. Disponible en: http://www. ub.edu/geocrit/xiv_everaldocosta.pdf 
COSTA, E. A paisagem barroca como memória estética nacional. Finisterra, 2016a, № 103, p. 6887. https://doi.org/10.18055/Finis4292

COSTA, E. Totalidade urbana e totalidade mundo: as cidades coloniais barrocas face à patrimonialização global, Tesis (Doctorado e Geografia). Universidade de São Paulo, 2011. http://www.teses. usp.br/teses/disponiveis/8/8136/tde-14032011-104656/pt-br.php

COSTA, E., \& MONCADA, J. Decolonialidad originaria latinoamericana y condicionamiento barroco del territorio novohispano: conventos, presidios y pueblos de indios. Cuadernos de Geografía, 2021, Vol. 2, No 30, p. 3-24. https://doi.org/10.15446/rcdg.v30n1.80924

CRESPO SANZ, A., \& FERNÁNDEZ WYTTENBACH, A. ¿Cartografía antigua o Cartografia historica? Estudios Geograficos, 2011, Vol. 72, № 271, p. 403-420. https://doi.org/10.3989/estgeogr.201115

DAVIDSON, D. Rivers and Empire: the Madeira route and the incorporation of the brazilian far west, 1737-1808. Tesis (Doctorado en Filosofía). Connecticut, Yale University, 1970.

FOCHLER-HAUKE, G. Las relaciones entre Geografía e Historia. En: Capítulos selectos de la Geografía Histórica, Universidad Nacional de Tucumán, Serie Didáctica, n. 6, 1953, p. 56-84 .

FONSECA, C. Arraiais e vilas d'el rei: espaço e poder nas Minas setecentistas. Belo Horizonte: Editora UFMG, 2011.

GARCÍA FERNÁNDEZ, E. Territorio y desafios para la planeación en México. PatryTer, Revista Latinoamericana e Caribenha de Geografia e Humanidades, 2020, Vol. 3, No 6, p. 01-15. https://doi. org/10.26512/patryter.v3i6.26644

GIL, T., \& BARLETA, L. Formas alternativas de visualização de dados na área de História: algumas notas de pesquisa. Revista História, 2015, No 173, p. 427-455. http://www.revistas.usp.br/revhistoria/article/view/106234

GEORGE, P. Os métodos da Geografia. São Paulo: Difusão Europeia do Livro, 1986.

GOMES, P. Quadros Geográficos: uma forma de ver, uma forma de pensar. Rio de Janeiro: Bertrand Brasil, 2017.

GONZÁLEZ LEIVA, J. Primeros levantamientos cartográficos generales de Chile con base científica: los mapas de Claudio Gay y Amado Pissis. Revista de Geografía Norte Grande, 2007, No 38, p. 21-44. http://dx.doi.org/10.4067/S0718-34022007000200002

GONZÁLEZ LEIVA, J y BERNEDO PINTO, P. Cartografía de la transformación de un territorio: La Araucanía 1852-1887. Revista de Geografía Norte Grande, Santiago, 2013, No 54, p. 179-198. http:// dx.doi.org/10.4067/S0718-34022013000100010

GRATALOUP, C. Introduction à la géohistoire. Paris: Armand Colin, 2015. 
HERZOG, T. Frontiers of Possession: Spain and Portugal in Europe and the Americas. Cambridge: Harvard University Press, 2015.

HOLANDA, S. B. Caminhos e fronteiras. Rio de Janeiro: Livraria José Olympio, 1957.

HOLANDA, S. B. Capítulos de Expansão Paulista. São Paulo: Companhia das Letras, 2014.

INGOLD, T. Une brève histoire des lignes. Bruxelles: Zones Sensibles, 2013.

LOIS, C. El mapa como metáfora o la espacialización del pensamiento. Terra Brasilis, No 6, p. 1-30. https://doi.org/10.4000/terrabrasilis.1553

LOIS, C. Isla vs. continente: un ensayo de historia conceptual. Revista de Geografia Norte Grande, Santiago, 2013, No 54, p. 85-107. http://dx.doi.org/10.4067/S0718-34022013000100006

MALULY, V. Como se fossem para o cabo do mundo: geohistória e cartografias sobre os caminhos e os descaminhos da Capitania de Goyaz. (Maestría en Geografía). Universidade de Brasília, 2017.

MALULY, V. Auguste de Saint-Hilaire e os territórios de exceção (Minas Gerais, 1816-1817). PatryTer, Revista Latinoamericana e Caribenha de Geografia e Humanidades, 2020, Vol. 3, No 6, p. 266-280. https://doi.org/10.26512/patryter.v3i6.27958

MONCADA, J. La cartografía de los ingenieros militares. Instrumento para el conocimiento del territorio. Revista de Geografía Norte Grande, 2018, No 69, p. 9-31. http://dx.doi.org/10.4067/S071834022018000100009

MONCADA, J., \& GÓMEZ-REY, P. Patrimonio geográfico mexicano del siglo XX. En: PEREDO, C. (ed.). La formación geográfica de México. México: Consejo Nacional para la Cultura y las Artes, 2011, p. 219-253.

MORAES, A. Bases da formação territorial do Brasil: o território colonial brasileiro no "longo" século XVI. São Paulo: Editora Hucitec, 2000.

MORAES, A. Geografia Histórica do Brasil: cinco ensaios, uma proposta e uma crítica. São Paulo: Annablume, 2009.

MOREIRA, R. Geografia e práxis. A presença do espaço na teoria e na prática geográficas. São Paulo: Contexto, 2012.

MORENO JERIA, R. El mapa de Chile y el plano de Santiago en la obra atribuida a Juan Ignacio Molina de 1776: los manuscritos perdidos. Revista de Geografía Norte Grande, 2018, No 69, p. 33-47. http://dx.doi.org/10.4067/S0718-34022018000100033

MORRISSEY, J. Illustrative Geographies. En: MORRISSEY, J.; NALLY, D.; STROHMAYER, U; WHELAN, Y (eds.). Key concepts in Historical Geography. Los Angeles, London, New Delhi, Singapore, Washington D.C.: SAGE Publications, 2014, p. 283-297. 
PALSKY, G. Des chiffres et des cartes: naissance et développment de la cartographie quantitative française au XIXe siècle. Paris: Comité des travaux historiques et scientifiques, 1996.

PITTE, J. La géographie historique au service des problèmes d'aujourd'hui. En: BOULANGER, P.; TROCHET, J. (eds.). Où en est la Géographie Historique? Paris: L’Harmattan, 2005, p. 192-211.

ROCHA JUNIOR, D. Relação das Contagens e Registros de Goiás-1748. Universitas Humanas, 2012, Vol. 9, No 1, p. 8-13. https://doi.org/10.5102/univhum.v9i1.1451

SAGREDO BAEZA, R. El futuro de Chile delineado en un mapa. Revista de Geografía Norte Grande, Santiago, 2018, No 69, p. 49-69. http://dx.doi.org/10.4067/S0718-34022018000100049

SALLES, G. Economia e escravidão na Capitania de Goiás. Goiânia: CEGRAF/UFG, 1992.

SANTOS, M. Por uma Geografia Nova. São Paulo: Hucitec-EdUSP, 1978.

SANTOS, M. A Natureza do Espaço. Sao Paulo: Hucitec-EdUSP, 1996.

SAUER, C. The Morphology of Landscape. California: University of California Press, 1996.

SOUZA, M. Territorio usado, rugosidades e patrimonio cultural: ensaio geográfico sobre o espaço banal. PatryTer, Revista Latinoamericana e Caribenha de Geografia e Humanidades, 2019, Vol. 2, No 4, p. 1-22, 2019. https://doi.org/10.26512/patryter.v2i4.26485

STRAFORINI, R. Tramas que brilham: sistema de circulação e a produção do território brasileiro no século XVIII. (Doctorado en Geografía). Universidade Federal do Rio de Janeiro, 2007.

VALLAUX, C. Les méthodes d'observation en géographie. Revue de Métaphysique et de Morale, 1927, Vol. 34, No 4, p. 473-488. https://www.jstor.org/stable/40896503?seq=1

VASCONCELOS, P. Questões metodológicas na geografia urbana histórica. Em VASCONCELOS, P. (ed.). Novos estudos de Geografia Urbana brasileira. Salvador: Editora da Univ. Federal da Bahia, 1999, p. 24-54.

VERDIER, N. Aux limites de la figuration cartographique. Le paysage comme lieu de la séparation entre vue et carte. Geostorie, Bolletino e Notiziario del Centro Italiano per gli Studi Storico-Geografici, 2016.

VIEIRA JÚNIOR, W. Cartografia da Capitania de Goyaz no século XVIII: intenção e representação. (Doctorado en Arquitetura y Urbanismo). Universidade de Brasília, 2015.

\section{Fuentes documentales}

ARQUIVO HISTÓRICO ULTRAMARINO. CARTA (cópia) do vigário de Goiás, [arraial de Santa Ana], Pedro Ferreira Brandão, ao desembargador Belchior do Rego de Andrade, sobre o estado das 
Minas de Goiás e a necessidade de medidas contundentes para se evitar os descaminhos dos quintos, AHU_ACL_CU_008, Cx. 1, D. 4. Lisboa: Arquivo Histórico Ultramarino.

ARQUIVO HISTÓRICO ULTRAMARINO. RELAÇÃO das contagens ou registros que tem o contrato das entradas nos continentes (da capitania de Goiás) e suas circunferências, com a distância que há entre eles e Vila Boa, AHU_ACL_CU_008, Cx. 5, D. 395. Lisboa: Arquivo Histórico Ultramarino.

ARQUIVO HISTÓRICO ULTRAMARINO. CONSULTA do Conselho Ultramarino, ao rei D. José, sobre a carta do intendente do arraial de São Félix, António Luís Lisboa, a respeito de como agiu com dois réus que ficaram pronunciados na devassa acerca do extravio do ouro e solicitando que se declare se será conveniente colocar um Registro na estrada por onde o extravio foi feito, AHU_ ACL_CU_008, Cx. 17, D. 1010. Lisboa: Arquivo Histórico Ultramarino.

BRAZIL. DRAWN AND PUBLISHED BY F. LUCAS JR., BALTIMORE. YOUNG \& DELLEKER SC. PHILADA. Conservado en la David Rumsey Map Collection. Accedido el 16 de junio de 2020. Disponible en: https://www.davidrumsey.com/luna/servlet/detail/RUMSEY 8 1 36045 1201247:Brazil-?sor$\mathrm{t}=$ pub_list_no_initialsort\%2Cpub_date\%2Cpub_list_no\%2Cseries_no\#

CARTA GEOGRÁFICA DA CAPITANIA DO MATO GROSSO. Conservado en la Biblioteca Nacional de Brasil en Rio de Janeiro. Accedido el 18 de enero de 2019. Disponible en: http://objdigital.bn.br/ acervo_digital/div_cartografia/cart525995.htm 
